\title{
ON THE CHROMATIN OF THE IMMATURE OOCYTE: FROM MORPHOLOGY TO FUNCTION AND REGULATORY MECHANISMS MEDIATED BY FOLLICULAR CELLS
}

\author{
VALENTINA LODDE $(* * *)$, SILVIA C. MODINA (*), \\ ALBERTO M. LUCIANO (*)
}

SunTO. - Nel suo commento intitolato 'Nuclear histochemistry: its history in fifty volumes', Maria Gabriella Manfredi Romanini (Eur J Histochem 2006; 50:79-81) descriveva "l'istochimica del nucleo"' come "una vera e propria tecnica di biologia molecolare in situ applicata allo studio sulla dinamica dei processi nucleari" e che "fa dell'approccio istochimico un insostituibile strumento per la comprensione della biologia cellulare”. Questa definizione perfettamente si adatta alle ricerche che hanno portato alla comprensione del processo di rimodellamento della cromatina che avviene nel nucleo dell'ovocita. Nell'ultimo decennio, questo processo che caratterizza la fase terminale della crescita e del differenziamento del gamete femminile, prima dell'ovulazione, ha ricevuto crescente attenzione da parte dei ricercatori data la sua rilevanza nel determinare la qualità del gamete stesso. Lo studio morfologico e istochimico della cromatina dell'ovocita è stato fondamentale per comprendere la biologia dell'ovocita ed ha posto le basi per studi molecolari e funzionali. Molti gruppi di ricerca nel panorama internazionale, incluso il nostro, stanno infatti conducendo ricerche finalizzate alla comprensione della relazione tra gli aspetti morfologici e quelli funzionali del processo di rimodellamento della cromatina; in questo articolo, riassumiamo i principali studi sui meccanismi che lo regolano e discutiamo alcune recenti scoperte sul ruolo fondamentale esercitato dalle cellule follicolari attraverso le giunzioni comunicanti che instaurano con l'ovocita.

(*) Laboratorio di Biologia della Riproduzione e dello Sviluppo, Dipartimento di Scienze Veterinarie per la Salute, la Produzione Animale e la Sicurezza Alimentare, Università degli Studi di Milano, Italy.

${ }^{(* *)}$ E-mail: valentina.lodde@unimi.it 
ABSTRACT. - In her comment entitled 'Nuclear histochemistry: its history in fifty volumes' (Eur J Histochem 2006; 50:79-81) Maria Gabriella Manfredi Romanini referred to "nuclear histochemistry" as a "real molecular biology in situ, applied to research on dynamic processes in the nucleus, which makes the microscopic and histochemical approach absolutely irreplaceable for the progress of our understanding of cell biology". These words perfectly exemplify the research path that is elucidating the process of remodeling of chromatin configuration within the nucleus of the mammalian oocyte. This process, which occurs towards the end of the oocyte differentiation phase before meiotic resumption, has received much attention in the last decade since it has a tremendous impact on the capability of the oocyte to generate an embryo after fertilization. The study of the oocyte chromatin by means of classical morphological and histochemical approaches has given a fundamental contribution to our understanding of oocyte biology and has paved the way to functional and mechanistic studies. Several research groups worldwide, including ours, are indeed dedicating a large amount of studies to find the relationship between morphological and functional aspects of the oocyte chromatin remodeling process, to reveal the molecular mechanisms involved, as well as to clarify the contribution of the follicular compartment. Here, we summarize some studies intended to give insight into the mechanism(s) regulating this complex process, including recent findings indicating that ovarian granulosa cells and their coupling with the oocyte through gap junctions are implicated in such a process.

\section{MAMMALIAN OOGENESIS}

The meiotic prophase $\mathrm{I}$ is the most complex and temporally extended phase of the process of meiosis in female mammals. During this phase, homologous chromosomes pair, exchange genetic material by recombination, and prepare for meiotic division. Classically, meiotic prophase I is divided into five stages (leptotene, zygotene, pachytene, diplotene, diakinesis), which are related to changes in chromosome morphology. In particular, during diplotene the proteinaceous synaptonemal complex (SC) which has formed in previous stages to stabilize paired chromosomes alignment, disassembles and chiasmata become visible. Each chiasma corresponds to a position where non-sister chromatids remain associated after crossing over, while the other regions are largely separated from each other.

Mammalian oocytes enter meiotic prophase I during fetal life, after a period of DNA replication. In the fetus, following leptotene, zygotene and pachytene stages, when chromosome recombination occurs, the meiosis arrests at the diplotene stage until after puberty. This protracted cell cycle arrest, also known as the dictyate stage, may 
last for many months or years depending on the species. At the dictyate stage, the oocyte chromosomes become less distinct and form a faint network (Beaumont and Mandl, 1962; Mandl, 1963), while a single layer of flattened granulosa cells surround the oocytes, thus forming the primordial follicles. These follicles are quiescent and constitute a pool where they will be recruited from for growth, and cyclically selected for ovulation during reproductive life. Concomitant to follicle development, the oocytes grow, and their diameters increase substantially due to considerable synthesis of cytoplasmic material. This is a crucial phase for the subsequent embryonic development.

At this stage, the chromosomes decondense and chromatin becomes transcriptionally active. Intense RNA synthesis is detectable in the oocyte nuclear compartment until it stops around the end of the growth phase. Once the growth phase is completed, the sole fully-grown oocytes selected for ovulation resume meiosis in response to the luteinizing hormone $(\mathrm{LH})$, while subordinate follicles, enclosing oocytes that have not been selected for ovulation, degenerate through atresia. Meiotic resumption occurs only after puberty is reached. Upon meiotic resumption, oocytes enter diakinesis, in which bivalents condense and individualize in preparation for the first meiotic divisions, the nuclear envelope breaks down, and meiosis continues to the metaphase of meiosis II. This process is referred to as oocyte maturation. At this stage, oocytes are released from the follicles through ovulation.

In laboratory practice, fully grown oocytes arrested at the diplotene I stage of most species are capable of spontaneous (LH independent) meiotic resumption once they are removed from their follicle and placed in a suitable culture environment. These oocytes are referred to as 'meiotically competent'.

More details on oocyte meiosis can be found in: De La Fuente (2006), Henriksen et al. (2003), Hyttel (2010) and Pawlowski and Cande (2005).

The nucleus of oocytes arrested at the diplotene I stage, which is named germinal vesicle $(\mathrm{GV})$, shows an intact nuclear envelope while the breakdown of nuclear envelope is known as GV breakdown (GVBD). Authors use the expression 'GV stage' to indicate when the oocyte is collected from the ovarian follicle, or even the period when the GV is clearly detectable within the oocyte before GVBD occurs. However 'GV stage' is not to be confused with the dictyate stage, since 
meiotic resumption is initiated well ahead of the nuclear envelope disappearance at GVBD.

\section{THE BEHAVIOR OF THE OOCYTE NUCLEUS IN MEIOTICALLY ARRESTED MAMMALIAN OOCYTE}

During meiotic arrest, and particularly during the oocyte growth phase leading to the formation of the fully-grown and differentiated oocyte, the nuclear chromatin is subjected to several levels of structural and functional regulation. These events include mechanisms acting both locally, on specific loci, and on a large scale to remodel wide portions of the oocyte genome. Morphologically, the chromosomes lose their individuality as well as their characteristic appearance and form a loose chromatin mass (Mandl 1963; Parfenov et al., 1989), which in turn undergoes profound and dynamic rearrangements within the GV before the meiotic resumption. We refer to these rearrangements as to 'large-scale chromatin configuration changes'.

\section{THE MORPHOLOGICAL DETERMINATION OF LARGE-SCALE CHROMATIN CONFIGURATION(S) IN MAMMALIAN OOCYTE}

The configuration of chromatin within the GV of mammalian oocytes can be assessed by means of different techniques for sample preparation and DNA staining. Early studies described chromatin configuration in growing, fully-grown and in vivo and/or in vitro maturing oocytes by using different methods that include DNA staining with Orcein after acetic alcohol fixation, light and electron microscopy techniques, DNA staining with Giemsa after hypotonic treatment and acetic alcohol fixation, and other histological methods for preparation and staining of ovarian sections (Mandl, 1963; Chouinard, 1975; Motlik, 1976,1978; Daguet, 1980; Fulka, 1981; Suss et al., 1988; Parfenov, 1989; Hirao et al., 1995).

More recently, the characterization of mammalian oocyte's chromatin configurations is based on fluorescence microscopy, in which DNA is stained with fluorescent dyes such as DAPI (4',6-diamidino2-phenylindole), Hoechst, propidium iodide, SYBR green, Sytox green, $\mathrm{CMA}_{3}$ (Chromomycin $\mathrm{A}_{3}$-Distamycin A-DAPI). After cumulus 
cells removal, oocytes are usually fixed in formaldehyde-containing solutions, stained and finally mounted on a slide for epifluorescence or laser scanning confocal microscopy analysis. The three-dimensional organization of the nucleus is typically preserved by mounting the samples between a coverslip and a glass slide supported by small columns of a mixture of vaseline and paraffin, and gently compressing them between slide and coverslip. As an alternative, chromatin configuration can be assessed in living (not fixed) oocytes by using an inverted fluorescence microscope. In this case, oocytes are stained with Hoechst dyes, which are cell-permeable and can bind to DNA both in live and in fixed cells and maintained in suspension in drops of medium for observation (Mattson and Albertini, 1990; Zuccotti et al., 1998; Lodde et al., 2007). Fluorescence microscopy is frequently used in combination with differential interference contrast microscopy and/or phase contrast microscopy in order to verify the presence of an intact nuclear envelope and/or the nucleolus. Finally, chromatin configuration has been assessed in ovarian cryosections after DNA fluorescent staining.

\section{LARGE-SCALE CHROMATIN CONFIGURATION(S) IN MAMMALIAN OOCYTE: COMMON FEATURES AND SPECIES-SPECIFIC CHARACTERISTICS}

Using these techniques, Matson and Albertini (1990) described changes in the organization of the mouse oocyte's chromatin with respect to progressive stages of follicular development. In their study, chromatin organization was classified into discrete patterns in which the chromatin mass is initially found dispersed throughout the nucleoplasm and appears mainly decondensed. Thereafter, chromatin condensation increases, and few chromatin foci start to associate with the nucleolar periphery until a complete rim of heterochromatin is formed in close apposition with the nucleolus, which is not active at this stage and is referred to as 'nucleolar like body', or nucleolar remnant. Many further studies confirmed these observations; therefore, the presence or absence of a complete rim of condensed chromatin around the nucleolus is considered to be the morphological discriminating element for the classification of mouse GV oocytes. Thus, the configuration in which the perinucleolar chromatin rim is absent is typically named 
'Non Surrounded Nucleolus' (NSN), while the configuration where the perinucleolar chromatin rim is present is termed 'Surrounded Nucleolus' (SN) ( Wickramasinghe et al., 1991; Debey et al., 1993; Zuccotti et al., 1995). Intermediate configurations have been described as 'partly NSN' and 'partly SN' (Bouniol-Baly et al., 1999). Notably, NSN type configuration is characteristic of oocytes isolated from primordial to growing preantral follicles; nonetheless, NSN oocytes are also found in antral follicles that indeed enclose both NSN and SN oocytes, with the percentage of SN oocytes increasing with the increase of the follicle diameter as well as the age of the animal.

By means of fluorescence microscopy, chromatin configurations have been assessed in GV oocytes of several mammals such as monkey (Schramm et al., 1993), pig (Bui et al., 2007), human (Combelles et al., 2003; Miyara et al., 2003), horse (Hinrichs 2010; Hinrichs et al., 1993; Franciosi et al., 2012), cattle (Fuhrer et al., 1989 Chohan and Hunter, 2003; Liu et al., 2006; Lodde et al., 2007), goat (Sui et al., 2005), sheep (Russo et al., 2007), rabbit (Wang et al., 2009), buffalo (Yousaf and Chohan, 2003), dog (Jin et al., 2006; Lee et al., 2008; Reynaud et al., 2009), ferret (Sun et al., 2009) and cat (Comizzoli et al., 2011).The formation of the perinucleolar rim of condensed chromatin is considered a typical feature in some of the above mentioned species, including human, pig and monkey. However, some exceptions have also been reported. For instance, chromatin condenses into a single compact clump instead of forming a clearly detectable rim around the nucleolus in cattle and horse (Lodde et al., 2007; Hinrichs, 2010; Franciosi et al., 2012). In cattle, in particular, oocytes are classified into four stages based on their chromatin configuration under fluorescence microscopy analysis: the GV0 stage is characterized by a diffuse filamentous pattern of chromatin in the whole nuclear area; the GV1 and GV2 configurations represent early and intermediate stages, respectively, of chromatin remodeling, a process starting with the appearance of few foci of condensation in GV1 oocytes and proceeding with the formation of distinct clumps of condensed chromatin in GV2 oocytes; the GV3 stage, where the maximum level of condensation is reached with chromatin organized into a single clump (Fig. 1). Nevertheless, further electron microscopy studies in cow, have revealed that chromatin in GV3 oocytes is mainly located near the inactive nucleolar remnant, that in turn appears to be partially or completely encapsulated by heterochromatin (Lodde et al., 2008). Thus GV3 chromatin configuration resembles $\mathrm{SN}$ configuration. 

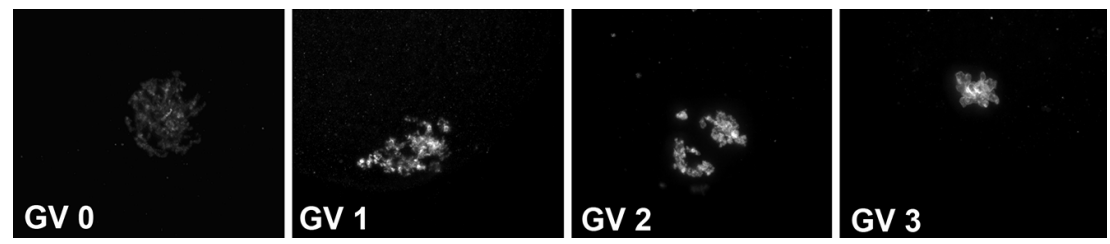

Fig. 1. Large-scale chromatin configuration in bovine oocytes, as assessed by confocal microscopy after nuclear staining with DAPI. Modified from Lodde et al. (2009).

Although many different criteria of classification together with a great variety of names and acronyms have been proposed, it is clear from the scientific literature that oocyte chromatin occurs in a less condensed state, in which it is dispersed throughout the nucleoplasm, and then progressively remodels into a more condensed state where its mass concentrates in a small area of the nucleoplasm, often in close association with the inactive nucleolus (Fig. 2). Importantly, increase of chromatin condensation can be related to progressive increase of the oocyte size, and to the formation and development of the antral follicle in all mammals studied so far (Fuhrer et al., 1989; Mattson and Albertini, 1990; Debey et al., 1993; Schramm et al., 1993; Zuccotti et al., 1995; Hinrichs and Schmidt, 2000; Combelles et al., 2002; Chohan and Hunter 2003; Miyara et al., 2003; Yousaf and Chohan 2003; Liu et al., 2006; Bui et al., 2007; Lodde et al., 2007; Russo et al., 2007; Wang et al., 2009; Comizzoli et al., 2011).

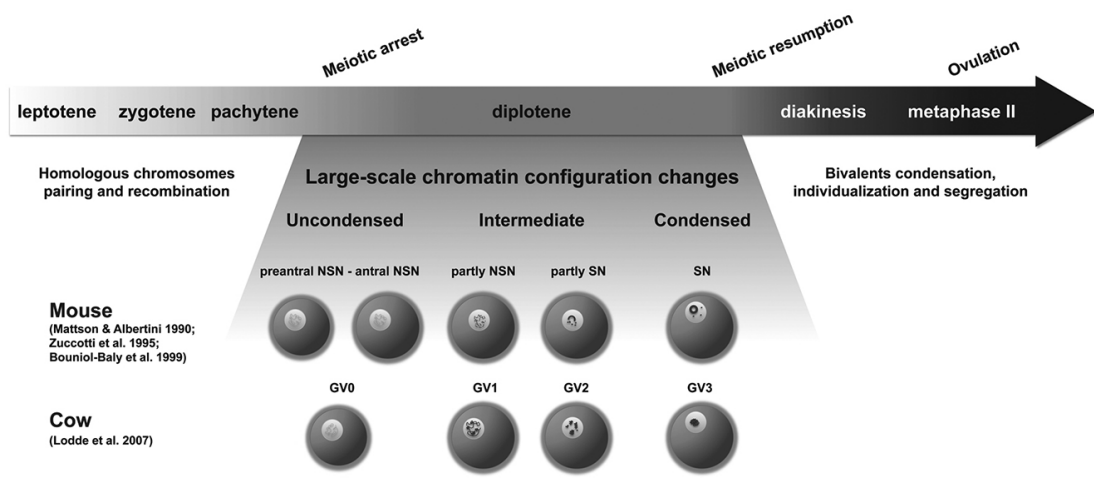

Fig. 2. Schematic representation of large-scale chromatin configuration changes in mammalian oocytes. Modified from Luciano and Lodde (2013). 


\section{THE KARYOSPHERE}

Both the exact role of the perinucleolar rim of heterochromatin and the mechanisms of its formation are not known. In mouse and human, this structure goes under the name of the 'karyosphere' (Parfenov et al., 1989; De La Fuente, 2004a, 2006) that is interpreted as 'the result of all chromosomes of the gametocyte joining in a limited nuclear volume with final formation of a single complex chromatin structure' (Gruzova and Parfenov, 1993). Considering this definition, it is clear that the single compact clump of chromatin found in GV3 bovine, in horse, and in other mammals resembles the karyosphere. Strikingly, a similar structure, named karyosome, exists in Drosophila as well as in many other phylogenetically distant organisms studied so far (Gruzova and Parfenov, 1993). It has been hypothesized, that this structure may fasten the chromosomes into a precise and restricted volume within the large GV (Gruzova and Parfenov, 1993). However, this hypothesis remains to be confirmed experimentally and the precise role of the karyosphere requires further studies. Undoubtedly, if we knew more about its composition, we would better understand its function. For example, studies in mouse oocytes have revealed that centromeres are an important component of the karyosphere (Longo et al., 2003; De La Fuente et al., 2004a,b; Bonnet-Garnier et al., 2012). This is crucial in that centromeres are the specific region in each chromosomes where the kinetochores, that provide interaction sites with the spindle microtubules, are assembled.

\section{FROM MORPHOLOGY TO FUNCTION: SIGNIFICANCE OF LARGE-SCALE CHROMATIN CONFIGURATION CHANGES ON OOCYTE COMPETENCE}

Much experimental evidence has confirmed the notion that oocyte competencies are acquired concomitantly with changes in largescale chromatin structure at sequential stages of oogenesis (Albertini et al., 2003; De La Fuente, 2006). More precisely, many studies indicate that meiotic competence acquisition is timely related with the appearance of early signs of chromatin condensation, while embryonic developmental competence is acquired before the highest level of chromatin condensation is reached (Lodde et al., 2007). 
For example, in many different mammalian species the oocytes that have a higher capability to mature in vitro are those isolated from large antral follicles, which in turn enclose a large proportion of oocytes showing advanced stages of chromatin condensation, in comparison with oocytes derived from smaller follicles where uncondensed chromatin more often occurs (Fuhrer et al., 1989; Wickramasinghe et al., 1991; Schramm et al., 1993; Hirao et al., 1995; Hinrichs and Schmidt, 2000; Yousaf and Chohan, 2003; Sui et al., 2005; Wang et al., 2009).

Direct experimental evidence that mouse oocytes with condensed chromatin $(\mathrm{SN})$ are more capable of in vitro early embryonic development was firstly provided by studies where living oocytes from antral follicles were divided into NSN and SN oocytes after staining with Hoechst 33342 and then subjected to standard procedures for in vitro embryo production (Zuccotti et al., 1998, 2002). These studies demonstrated that NSN oocytes did not develop beyond the two-cell stage, whereas SN oocytes progressed into the blastocyst stage. In cattle, a similar experimental approach gave further insights into this process (Lodde et al., 2007). In fact in cattle, when oocytes were matured under appropriate culture condition (Luciano et al., 2005), oocytes with a GV0 configuration showed a very limited capability to resume and complete meiosis I, while virtually all the GV1, GV2 and GV3 oocytes were able to reach the metaphase II (MII) stage, despite their GV configuration. On the contrary, after in vitro fertilization and embryo culture, only a limited proportion of GV1 oocytes reached the blastocyst stage, while GV2 and GV3 oocytes showed a higher embryonic developmental capacity (Lodde et al., 2007).

\section{THE INTERPLAY BETWEEN LARGE-SCALE CHROMATIN CONFIGURATION CHANGES AND TRANSCRIPTION}

Chromatin configuration changes are temporally correlated with the onset of transcriptional silencing in the oocyte nucleus (BouniolBaly et al., 1999; Christians et al., 1999; De La Fuente and Eppig 2001; Liu and Aoki 2002; Miyara et al., 2003; Sui et al., 2005; Lodde et al., 2008; Wang et al., 2009; Comizzoli et al., 2011). In the mouse, NSN oocytes are transcriptionally active and synthesize all classes of RNA, 
whereas the acquisition of the SN configuration correlates with global repression of transcription (Bouniol-Baly et al., 1999; Christians et al., 1999; De La Fuente and Eppig, 2001; Liu and Aoki, 2002; Miyara et al., 2003; Abe et al., 2010). Similarly, in bovine oocytes the GV0 configuration, with uncondensed chromatin, is associated with high levels of transcription, which in turn is globally silenced in GV3 oocytes. Importantly, a major drop of transcription is temporally linked to initial chromatin condensation that occurs during the GV0 to GV1 transition (Lodde et al., 2008; Luciano et al., 2011).

Consistently with the status of global transcriptional repression that characterizes oocytes with highly condensed chromatin, their nucleoli are typically found as inactive structures, referred to as 'nucleolar like bodies' (NLB) or 'nucleolar remnants'. (Parfenov et al., 1989; Debey et al., 1993; Fair et al., 1996; Bouniol-Baly et al., 1999; Miyara et al., 2003; Bjerregaard et al., 2004; Lodde et al., 2008). On the contrary, nucleoli of bovine oocytes with decondensed chromatin (GV0 stage) show the typical morphology of nucleoli that are actively engaged in rRNA synthesis, (Fair et al., 1996; Lodde et al., 2008).

Clearly, such diversities reflect dissimilar metabolic properties of oocytes showing diverse chromatin configurations, which in turn could be the basis for different capacities of in vitro development, as the synthesis and storage of maternal transcripts before transcriptional repression enables the oocyte to complete meiosis and to initiate embryogenesis. In this view, oocytes with uncondensed chromatin are still in the process of accumulating transcripts and other molecules indispensable for further development. Recently, the metabolic profile of two classes of oocytes (i.e., MII stage oocytes obtained after in vitro maturation of NSN or SN antral oocytes) were definitively confirmed to differ by microarray analysis. Importantly, Oct-4 expression was shown to be dysregulated in MII oocytes obtained from NSN oocytes, when compared with MII from SN, which also leads to an altered expression of other important genes involved in several biochemical pathways (Zuccotti et al., 2008, 2009, 2011).

The relationship between chromatin configuration and transcription is of central importance and may indicate that chromatin architecture regulates transcriptional activity directly. The reciprocal connection of the two events is, to some extent, demonstrated by the recent finding that NSN to SN transition is significantly impaired and transcriptional repression is incomplete in mouse oocytes in which the developmental 
pluripotency-associated protein 3 (Dppa3, also known as PGC7 or Stella) is silenced (Liu et al., 2011). However, studies in mouse have illustrated that transition into the SN configuration is not strictly necessary for transcriptional silencing observed in the fully-grown oocyte. Both large-scale chromatin configuration changes and global transcriptional silencing have been indeed experimentally dissociated in both in vivo and in vitro studies. For example, in oocytes from nucleoplasmin-2-null females, transcriptional silencing occurs even though chromatin does not organize into the $\mathrm{SN}$ configuration, while transcription remains silenced when the SN configuration is disrupted and reverted to an NSN-like configuration after treatment with TSA (De La Fuente et al., 2004a). On the other hand, transcriptional silencing fails to occur in oocytes from histone 3 Lysine 4 methyltransferase (MLL2)-conditional-knockout females, even though chromatin reorganizes into the $\mathrm{SN}$ configuration (AndreuVieyra et al., 2010). Therefore, large-scale chromatin condensation does not seem to be the direct and primary cause of transcriptional silencing and, conversely, the establishment of the $\mathrm{SN}$ configuration does not depend primarily on the acquisition of global transcriptional repression. Hence, these two events might be controlled, at least partially, by independent mechanisms.

\section{MOLECULAR MECHANISMS CONTROLLING LARGE-SCALE CHROMATIN CONFIGURATION CHANGES}

The molecular mechanisms regulating changes in large-scale chromatin configuration in the mammalian oocyte are largely unknown. Clearly, multiple factors contribute to this process.

Some indications on the mechanisms regulating chromatin rearrangements come from studies in mouse. In this species, interference with the expression and function of several molecules affects the process of chromatin reorganization into the SN configuration. For example, nucleoplasmin 2 (Burns et al., 2003; De La Fuente et al., 2004a), and DPPA3 depletions (Liu et al., 2011) all prevent the establishment of the $\mathrm{SN}$ configuration in mouse oocytes indicating that these molecules could have important function in this process. Histone tail modifications (acetylation, methylation, phosphorylation, ubiquitination, etc.) as well as changes in the global level of DNA methylation, known to influence chromatin structure and function in many biologi- 
cal systems, have been also proposed as possible modulators of largescale chromatin configuration in mammalian oocytes (for examples see: Akiyama et al., 2004; Endo et al., 2005; De La Fuente 2006; Ivanovska and Orr-Weaver, 2006; Russo et al., 2007; Meglicki et al., 2008; Lodde et al., 2009; Franciosi et al., 2012). In bovine, for example, the transition from the GV0 to the GV1 configuration is associated with a substantial increase of global DNA methylation (Lodde et al., 2009), which well correlates with the decreased transcriptional activity. Given the biological importance of the process of chromatin remodeling, clearly more efforts are required to reveal its regulatory mechanisms.

\section{THE KEEN LINKAGE BETWEEN CUMULUS GRANULOSA CELLS AND MORPHO-FUNCTIONAL LARGE-SCALE CHROMATIN CONFIGURATION CHANGES}

Studies in mouse and bovine indicate that ovarian granulosa cells and their coupling with the oocytes through gap junctions exert an important role in the process of chromatin remodeling. In the mouse, when gap junction mediated communication (GJC) between the oocyte and cumulus cells is perturbed, due to targeted deletion of the connexin 37 gene (Gja4), transcriptional silencing (which normally occurs in wild type mice during oocyte growth) is impaired, and chromatin remains in an uncondensed state instead of compacting into the SN configuration (Carabatsos et al., 2000). Similarly, when mouse oocytes from preantral follicles are cultured in vitro, the presence of associated granulosa cells is necessary for the coordination of large-scale chromatin configuration with the onset of transcriptional silencing, at chronological stages equivalent to those of in vivo grown oocytes. On the contrary, if the oocytes are cultured in the absence of granulosa cells, transcriptional silencing fails to occur and chromatin does not organize into the $\mathrm{SN}$ configuration but remains uncondensed with transcription sites that appear to be uniformly distributed instead of being more pronounced in certain chromatin areas, as judged by Br-UTP incorporation (De La Fuente and Eppig, 2001).

The pivotal role of GJC in the modulation of chromatin structure and function has been confirmed in bovine oocyte-cumulus cells complexes. In fact, at the time of collection, the pattern of uncondensed chromatin in GV0 oocytes associates with a fully open state of GJC, 
whereas the percentage of oocytes with functionally open communications significantly decreases with the increase of chromatin compaction, from GV1 to GV3 oocytes (Lodde et al., 2007). Furthermore, when cumulus oocytes complexes from early antral follicles, in which chromatin is mostly decondensed (GV0), are cultivated in vitro with low concentrations of FSH, the maintenance of a patent bidirectional coupling allows chromatin to gradually organize into the GV1 configuration, thus acquiring the ability to mature and be fertilized in vitro (Luciano et al., 2011). On the contrary, in the absence of hormonal treatment, coupling is not sustained and chromatin remains mainly in an uncondensed state. Strikingly, treatment with higher doses of FSH does not support functional coupling either, and it seems likely to force the oocyte to resume meiosis without an orderly remodeling of chromatin configuration. Thus, the apparent increased ability to resume meiosis is not accompanied by an equal increase of fertilization competence (Luciano et al., 2011).

Additional experiments in the bovine model, where low doses of FSH sustain GJC functionality in cumulus oocytes complexes from early antral follicles, gave further insight into the mechanisms by which GJC may modulate changes in large-scale chromatin configuration and transcription. In this system, indeed, treatment with the uncoupler 1heptanol induces sudden condensation of chromatin and decrease in transcription. However, this effect is nullified by addition of cilostamide to the culture medium (Luciano et al., 2011). This indicates that the functional status of GJC may affect both transcriptional activity and remodeling of large-scale chromatin configuration, potentially through cAMP-dependent mechanism(s), because cilostamide acts as a specific inhibitor of the oocyte-specific PDE3, an enzyme-degrading cAMP ( Richard et al., 2001; Conti et al., 2002; Sasseville et al., 2009). Besides the well-characterized mechanisms of action by which cAMP is known to regulate meiotic resumption (reviewed in Bilodeau-Goeseels, 2011; Downs, 2010), these results may suggest that cAMP could be also involved in the control of the activity of factors that modulate transcription and large-scale chromatin remodeling during the final phase of oocyte growth and before the resumption of meiosis.

Finally, the importance of a functional bidirectional communication between oocyte and cumulus cells through gap junction in fullygrown oocyte has been demonstrated in bovine and pig. Moreover also in this case, cAMP has been shown to have an important role (Modina 
et al., 2001; Luciano et al., 2004; Dieci et al., 2013; Lodde et al., 2013; Franciosi et al., 2014).

\section{IMPLICATIONS OF LARGE-SCALE CHROMATIN CONFIGURATIONS IN BASIC SCIENCE AND IN ASSISTED REPRODUCTIVE TECHNOLOGIES}

It is clear that the analysis of the functional and structural modifications that accompany large-scale chromatin configuration changes in the oocyte will have wide-ranging implications for understanding the role of nuclear organization in meiosis, the events of nuclear reprogramming, and the spatio-temporal regulation of gene expression during oocyte and embryo development.

Assessment of large-scale chromatin configurations has also large implication in assisted reproductive technologies (ART) in humans and domestic species. It has been shown that different patterns of chromatin configuration are indicative of different metabolic properties. Many studies support the idea that treatments aimed to improve the developmental competence of immature oocytes can have a different effect with "pre-maturation culture" depending on the metabolic status of the oocyte at the moment of its collection from the follicular environment (Nogueira et al., 2006; Vanhoutte et al., 2008, 2009). Thus, oocyte chromatin configuration could represent a morphological marker to select a population of oocytes with different cultural needs as well as for the optimization of 'customized' culture system that would fulfill specifically requirements of each GV class, thus being of great help in the field of ART.

\section{REFERENCES}

Abe K, Inoue A, Suzuki MG, Aoki F. Global gene silencing is caused by the dissociation of RNA polymerase II from DNA in mouse oocytes. J Reprod Dev 2010;56:502507.

Akiyama T, Kim JM, Nagata M, Aoki F. Regulation of histone acetylation during meiotic maturation in mouse oocytes. Mol Reprod Dev 2004;69:222-227.

Albertini DF, Sanfins A, Combelles CM. Origins and manifestations of oocyte maturation competencies. Reprod Biomed Online 2003;6:410-415.

Andreu-Vieyra CV, Chen R, Agno JE, Glaser S, Anastassiadis K, Stewart AF et al. 
MLL2 is required in oocytes for bulk bistone 3 lysine 4 trimetbylation and transcriptional silencing. PLoS biology 2010;8.

Beaumont HM, Mandl AM. A Quantitative and Cytological Study of Oogonia and Oocytes in the Foetal and Neonatal Rat. Proc R Soc Lond B 1962;155:557-579.

Bilodeau-Goeseels S. Cows are not mice: the role of cyclic AMP, phosphodiesterases, and adenosine monophosphate-activated protein kinase in the maintenance of meiotic arrest in bovine oocytes. Mol Reprod Dev 2011;78:734-743.

Bjerregaard B, Wrenzycki C, Philimonenko VV, Hozak P, Laurincik J, Niemann H et al. Regulation of ribosomal RNA synthesis during the final phases of porcine oocyte growth. Biol Reprod 2004;70:925-935.

Bonnet-Garnier A, Feuerstein P, Chebrout M, Fleurot R, Jan HU, Debey P et al. Genome organization and epigenetic marks in mouse germinal vesicle oocytes. Int J Dev Biol 2012;56:877-887.

Bouniol-Baly C, Hamraoui L, Guibert J, Beaujean N, Szollosi MS, Debey P. Differential transcriptional activity associated with chromatin configuration in fully grown mouse germinal vesicle oocytes. Biol Reprod 1999;60:580-587.

Bui HT, Van Thuan N, Kishigami S, Wakayama S, Hikichi T, Ohta H et al. Regulation of chromatin and chromosome morphology by histone $\mathrm{H} 3$ modifications in pig oocytes. Reproduction 2007;133:371-382.

Burns KH, Viveiros MM, Ren Y, Wang P, DeMayo FJ, Frail DE et al. Roles of NPM2 in chromatin and nucleolar organization in oocytes and embryos. Science 2003;300:633-636.

Carabatsos MJ, Sellitto C, Goodenough DA, Albertini DF. Oocyte-granulosa cell beterologous gap junctions are required for the coordination of nuclear and cytoplasmic meiotic competence. Dev Biol 2000;226:167-179.

Chohan KR, Hunter AG. Meiotic competence of bovine fetal oocytes following in vitro maturation. Anim Reprod Sci 2003;76:43-51.

Christians E, Boiani M, Garagna S, Dessy C, Redi CA, Renard JP et al. Gene expression and chromatin organization during mouse oocyte growth. Dev Biol 1999;207:76-85.

Combelles CM, Albertini DF, Racowsky C. Distinct microtubule and chromatin characteristics of buman oocytes after failed in-vivo and in-vitro meiotic maturation. Hum Reprod 2003;18:2124-2130.

Combelles CM, Cekleniak NA, Racowsky C, Albertini DF. Assessment of nuclear and cytoplasmic maturation in in-vitro matured buman oocytes. Hum Reprod 2002;17:1006-1016.

Comizzoli P, Pukazhenthi BS, Wildt DE. The competence of germinal vesicle oocytes is unrelated to nuclear chromatin configuration and strictly depends on cytoplasmic quantity and quality in the cat model. Human reproduction 2011;26:2165-2177.

Conti M, Andersen CB, Richard F, Mehats C, Chun SY, Horner K et al. Role of cyclic nucleotide signaling in oocyte maturation. Mol Cell Endocrinol 2002;187:153-159.

Daguet MC. In vivo change in the germinal vesicle of the sow oocyte during the follicular phase before the ovulatory LH surge. Reprod Nutr Dev 1980;20:673-680.

De La Fuente R. Chromatin modifications in the germinal vesicle $(G V)$ of mammalian oocytes. Dev Biol 2006;292:1-12. 
De La Fuente R, Eppig JJ. Transcriptional activity of the mouse oocyte genome: companion granulosa cells modulate transcription and chromatin remodeling. Dev Biol 2001;229:224-236.

De La Fuente R, Viveiros MM, Burns KH, Adashi EY, Matzuk MM, Eppig JJ. Major chromatin remodeling in the germinal vesicle $(G V)$ of mammalian oocytes is dispensable for global transcriptional silencing but required for centromeric beterochromatin function. Dev Biol 2004a;275:447-458.

De La Fuente R, Viveiros MM, Wigglesworth K, Eppig JJ. ATRX, a member of the SNF2 family of helicase/ATPases, is required for chromosome alignment and meiotic spindle organization in metaphase II stage mouse oocytes. Dev Biol 2004b;272:1-14.

Debey P, Szollosi MS, Szollosi D, Vautier D, Girousse A, Besombes D. Competent mouse oocytes isolated from antral follicles exhibit different chromatin organization and follow different maturation dynamics. Mol Reprod Dev 1993;36:59-74.

Dieci C, Lodde V, Franciosi F, Lagutina I, Tessaro I, Modina SC et al. The effect of cilostamide on gap junction communication dynamics, chromatin remodeling, and competence acquisition in pig oocytes following parthenogenetic activation and nuclear transfer. Biol Reprod 2013;89:68.

Downs SM. Regulation of the G2/M transition in rodent oocytes. Mol Reprod Dev 2010;77:566-585.

Endo T, Naito K, Aoki F, Kume S, Tojo H. Changes in histone modifications during in vitro maturation of porcine oocytes. Mol Reprod Dev 2005;71:123-128.

Fair T, Hyttel P, Greve T, Boland M. Nucleus structure and transcriptional activity in relation to oocyte diameter in cattle. Mol Reprod Dev 1996;43:503-512.

Franciosi F, Coticchio G, Lodde V, Tessaro I, Modina SC, Fadini R et al. Natriuretic peptide precursor $C$ delays meiotic resumption and sustains gap junction-mediated communication in bovine cumulus-enclosed oocytes. Biol Reprod 2014;91:61.

Franciosi F, Lodde V, Goudet G, Duchamp G, Deleuze S, Douet C et al. Changes in histone $\mathrm{H} 4$ acetylation during in vivo versus in vitro maturation of equine oocytes. Mol Hum Reprod 2012;18:243-252.

Fuhrer F, Mayr B, Schellander K, Kalat M, Schleger W. Maturation competence and chromatin behaviour in growing and fully grown cattle oocytes. Zentralbl Veterinarmed A 1989;36:285-291.

Gruzova MN, Parfenov VN. Karyosphere in oogenesis and intranuclear morphogenesis. International review of cytology 1993;144:1-52.

Henriksen C, Williams R, $2^{\text {nd }}$, Page NE, Worral PS. Responding to nursing's agenda for the future. Where do we stand on recruitment and retention? Nursing leadership forum 2003;8:78-84.

Hinrichs K. The equine oocyte: factors affecting meiotic and developmental competence. Mol Reprod Dev 2010;77:651-661.

Hinrichs K, Schmidt AL. Meiotic competence in horse oocytes: interactions among chromatin configuration, follicle size, cumulus morphology, and season. Biol Reprod 2000;62:1402-1408.

Hinrichs K, Schmidt AL, Friedman PP, Selgrath JP, Martin MG. In vitro maturation of 
borse oocytes: characterization of chromatin configuration using fluorescence microscopy. Biol Reprod 1993;48:363-370.

Hirao Y, Tsuji Y, Miyano T, Okano A, Miyake M, Kato S et al. Association between p34cdc2 levels and meiotic arrest in pig oocytes during early growth. Zygote 1995;3:325-332.

Hyttel P. Gametogenesis. In: Essentials of domestic animal embriology. Hyttel P, Sinowatz F, Vejlsted, eds.: Saunders Elsevier 2010: pp. Number of 32-56.

Ivanovska I, Orr-Weaver TL. Histone modifications and the chromatin scaffold for meiotic chromosome architecture. Cell Cycle 2006;5:2064-2071.

Jin YX, Lee HS, Yin XJ, Cui XS, Kong IK, Kim NH. Chromatin, microtubule and microfilament configurations in the canine oocyte. Reprod Fertil Dev 2006;18:849-856.

Lee HS, Yin XJ, Jin YX, Kim NH, Cho SG, Bae IH et al. Germinal vesicle chromatin configuration and meiotic competence is related to the oocyte source in canine. Anim Reprod Sci 2008;103:336-347.

Liu H, Aoki F. Transcriptional activity associated with meiotic competence in fully grown mouse GV oocytes. Zygote 2002;10:327-332.

Liu Y, Sui HS, Wang HL, Yuan JH, Luo MJ, Xia P et al. Germinal vesicle chromatin configurations of bovine oocytes. Microscopy research and technique 2006;69:799-807.

Liu YJ, Nakamura T, Nakano T. Essential Role of DPPA3 for Chromatin Condensation in Mouse Oocytogenesis. Biol Reprod 2011.

Lodde V, Franciosi F, Tessaro I, Modina SC, Luciano AM. Role of gap junction-mediated communications in regulating large-scale chromatin configuration remodeling and embryonic developmental competence acquisition in fully grown bovine oocyte. J Assist Reprod Genet 2013;30:1219-1226.

Lodde V, Modina S, Galbusera C, Franciosi F, Luciano AM. Large-scale chromatin remodeling in germinal vesicle bovine oocytes: Interplay with gap junction functionality and developmental competence. Mol Reprod Dev 2007;74:740-749.

Lodde V, Modina S, Maddox-Hyttel P, Franciosi F, Lauria A, Luciano AM. Oocyte morphology and transcriptional silencing in relation to chromatin remodeling during the final phases of bovine oocyte growth. Mol Reprod Dev 2008;75:915-924.

Lodde V, Modina SC, Franciosi F, Zuccari E, Tessaro I, Luciano AM. Localization of DNA methyltransferase-1 during oocyte differentiation, in vitro maturation and early embryonic development in cow. Eur J Histochem 2009;53:187-195.

Longo F, Garagna S, Merico V, Orlandini G, Gatti R, Scandroglio R et al. Nuclear localization of NORs and centromeres in mouse oocytes during folliculogenesis. Mol Reprod Dev 2003;66:279-290.

Luciano AM, Franciosi F, Modina SC, Lodde V. Gap Junction-Mediated Communications Regulate Chromatin Remodeling During Bovine Oocyte Growth and Differentiation Through cAMP-Dependent Mechanism(s). Biol Reprod 2011;85:1252-1259.

Luciano AM, Lodde V. Changes of Large-Scale Chromatin Configuration During Mammalian Oocyte Differentiation. In: Oogenesis. Coticchio G, Albertini DF, De Santis L, eds.: Springer London 2013: pp. Number of 93-108. 
Luciano AM, Lodde V, Beretta MS, Colleoni S, Lauria A, Modina S. Developmental capability of denuded bovine oocyte in a co-culture system with intact cumulusoocyte complexes: role of cumulus cells, cyclic adenosine 3',5'-monophosphate, and glutathione. Mol Reprod Dev 2005;71:389-397.

Luciano AM, Modina S, Vassena R, Milanesi E, Lauria A, Gandolfi F. Role of intracellular cyclic adenosine 3',5'-monophosphate concentration and oocyte-cumulus cells communications on the acquisition of the developmental competence during in vitro maturation of bovine oocyte. Biol Reprod 2004;70:465-472.

Mandl A. Pre-ovulatory changes in the oocyte of the adult rat. Proc R Soc Lond B 1963;158:105-118.

Mattson BA, Albertini DF. Oogenesis: chromatin and microtubule dynamics during meiotic prophase. Mol Reprod Dev 1990;25:374-383.

Meglicki M, Zientarski M, Borsuk E. Constitutive beterochromatin during mouse oogenesis: the pattern of histone H3 modifications and localization of HP1alpha and HP1beta proteins. Mol Reprod Dev 2008;75:414-428.

Miyara F, Migne C, Dumont-Hassan M, Le Meur A, Cohen-Bacrie P, Aubriot FX et al. Chromatin configuration and transcriptional control in buman and mouse oocytes. Mol Reprod Dev 2003;64:458-470.

Modina S, Luciano AM, Vassena R, Baraldi-Scesi L, Lauria A, Gandolfi F. Oocyte developmental competence after in vitro maturation depends on the persistence of cumulus-oocyte comunications which are linked to the intracellular concentration of cAMP. Ital J Anat Embryol 2001;106:241-248.

Nogueira D, Ron-El R, Friedler S, Schachter M, Raziel A, Cortvrindt R et al. Meiotic arrest in vitro by phosphodiesterase 3-inhibitor enhances maturation capacity of buman oocytes and allows subsequent embryonic development. Biol Reprod 2006;74:177-184.

Parfenov V, Potchukalina G, Dudina L, Kostyuchek D, Gruzova M. Human antral follicles: oocyte nucleus and the karyosphere formation (electron microscopic and autoradiographic data). Gamete Res 1989;22:219-231.

Pawlowski WP, Cande WZ. Coordinating the events of the meiotic prophase. Trends in cell biology 2005;15:674-681.

Reynaud K, de Lesegno CV, Chebrout M, Thoumire S, Chastant-Maillard S. Follicle population, cumulus mucification, and oocyte chromatin configuration during the periovulatory period in the female dog. Theriogenology 2009;72:1120-1131.

Richard FJ, Tsafriri A, Conti M. Role of phosphodiesterase type 3 A in rat oocyte maturation. Biol Reprod 2001;65:1444-1451.

Russo V, Martelli A, Berardinelli P, Di Giacinto O, Bernabo N, Fantasia D et al. Modifications in chromatin morphology and organization during sheep oogenesis. Microsc Res Tech 2007.

Sasseville M, Gagnon MC, Guillemette C, Sullivan R, Gilchrist RB, Richard FJ. Regulation of gap junctions in porcine cumulus-oocyte complexes: contributions of granulosa cell contact, gonadotropins, and lipid rafts. Molecular endocrinology 2009;23:700-710.

Schramm RD, Tennier MT, Boatman DE, Bavister BD. Chromatin configurations and 
meiotic competence of oocytes are related to follicular diameter in nonstimulated rhesus monkeys. Biol Reprod 1993;48:349-356.

Sui HS, Liu Y, Miao DQ, Yuan JH, Qiao TW, Luo MJ et al. Configurations of germinal vesicle $(G V)$ chromatin in the goat differ from those of other species. Mol Reprod Dev 2005;71:227-236.

Sun X, Li Z, Yi Y, Ding W, Chen J, Engelhardt JF et al. Chromatin configurations in the ferret germinal vesicle that reflect developmental competence for in vitro maturation. Reproduction in domestic animals = Zuchthygiene 2009;44:320-325.

Suss U, Wuthrich K, Stranzinger G. Chromosome configurations and time sequence of the first meiotic division in bovine oocytes matured in vitro. Biol Reprod 1988;38:871-880.

Vanhoutte L, Nogueira D, De Sutter P. Prematuration of buman denuded oocytes in a three-dimensional co-culture system: effects on meiosis progression and developmental competence. Hum Reprod 2009;24:658-669.

Vanhoutte L, Nogueira D, Gerris J, Dhont M, De Sutter P. Effect of temporary nuclear arrest by phosphodiesterase 3-inbibitor on morphological and functional aspects of in vitro matured mouse oocytes. Mol Reprod Dev 2008;75:1021-1030.

Wang HL, Sui HS, Liu Y, Miao DQ, Lu JH, Liang B et al. Dynamic changes of germinal vesicle chromatin configuration and transcriptional activity during maturation of rabbit follicles. Fertil Steril 2009;91:1589-1594.

Wickramasinghe D, Ebert KM, Albertini DF. Meiotic competence acquisition is associated with the appearance of M-phase characteristics in growing mouse oocytes. Dev Biol 1991;143:162-172.

Yousaf MR, Chohan KR. Nuclear morphology, diameter and meiotic competence of buffalo oocytes relative to follicle size. Reprod Fertil Dev 2003;15:223-229.

Zuccotti M, Merico V, Bellone M, Mulas F, Sacchi L, Rebuzzini P et al. Gatekeeper of pluripotency: a common Oct4 transcriptional network operates in mouse eggs and embryonic stem cells. BMC genomics 2011;12:1-13.

Zuccotti M, Merico V, Sacchi L, Bellone M, Brink TC, Bellazzi R et al. Maternal Oct-4 is a potential key regulator of the developmental competence of mouse oocytes. BMC Dev Biol 2008;8:97.

Zuccotti M, Merico V, Sacchi L, Bellone M, Brink TC, Stefanelli M et al. Oct-4 regulates the expression of Stella and Foxj2 at the Nanog locus: implications for the developmental competence of mouse oocytes. Human reproduction 2009;24:2225-2237.

Zuccotti M, Piccinelli A, Rossi PG, Garagna S, Redi CA. Chromatin organization during mouse oocyte growth. Mol Reprod Dev 1995;41:479-485.

Zuccotti M, Ponce RH, Boiani M, Guizzardi S, Govoni P, Scandroglio R et al. The analysis of chromatin organisation allows selection of mouse antral oocytes competent for development to blastocyst. Zygote 2002;10:73-78.

Zuccotti M, Rossi PG, Martinez A, Garagna S, Forabosco A, Redi CA. Meiotic and developmental competence of mouse antral oocytes. Biol Reprod 1998;58:700-704. 